\title{
A religious perspective
}

ECUMENICAL PATRIARCH BARTHOLOMEW

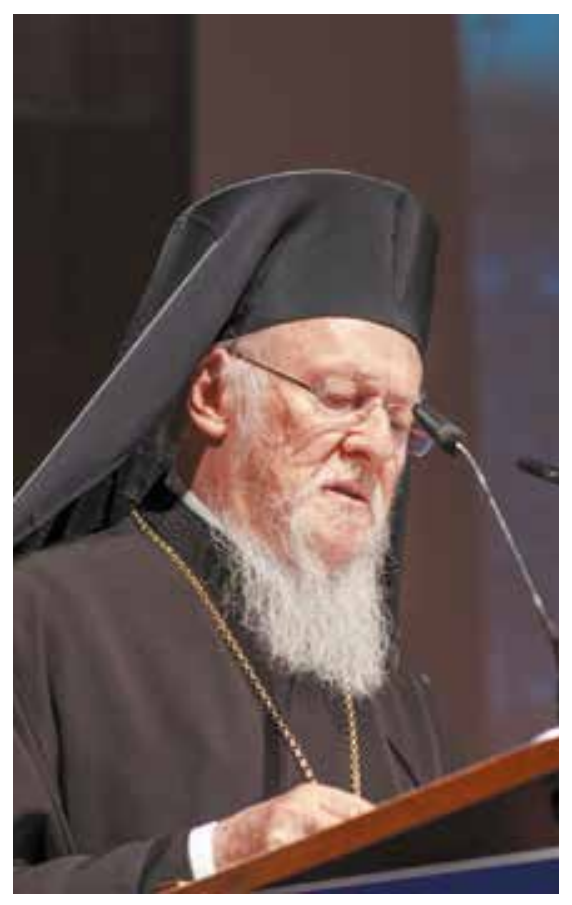

If there is one thing that we have learned from the global crisis and scarcity of clean water, it is that we cannot resolve the destruction of our planet or the depletion of its natural resources single-handedly. These problems clearly transcend national and political boundaries, just as they certainly exceed commercial and technological interests. They require working in cooperation, not venturing in isolation. They require building bridges. This is the message that we are called to accept and assimilate.

However, building bridges presents us with particular challenges as well as specific conditions:

Firstly, it requires an element of humanism. It means reaching inside the human heart, which is a bridge to the whole world. We must admit that we have failed in our vocation to care for God's creation. We have not done so deliberately; but whether through ignorance or indifference, whether as a result of selfishness or carelessness, we have not been ethical or faithful to our obligation to share the earth's resources with others. We have forgotten that water is God's gift to all people in every generation.

Secondly, it demands a sense of humility. It means reaching across barriers that we have created and zones where we feel complacent. We must accept that none of us can resolve these questions without working closely with other segments of society and disciplines of science. Politicians are called to listen to their 
constituents; and people are obliged to lean on their politicians. Corporations are supposed to protect the privileges of all; they cannot develop at the expense of others. Faith communities must pay attention to the warnings of the scientific community; and science must recognise the importance of mobilising the energy of religion.

Finally, it involves the dimension of hope. It means recognising that there is a power that transcends our limitations and a grace that fulfils our intentions. This factor is the unique contribution brought to the table by the Church. As the author of the Letter to the Hebrews (II:I-3) writes: 'Faith is the assurance of things hoped for, the conviction of things not seen [...] It is by faith that we understand that the world was created by the word of God.' Faith provides the hope that this world is larger than any one of us, that this world has more than enough for all of us, and that this world belongs to all of us as a precious gift from God.

These, then, are the challenges and conditions for building bridges: humanism, humility, and hope. In many ways, these are fundamental spiritual attributes and essential moral virtues. Because building bridges means building compassion and community. Building bridging signifies building stewardship and sustainability. And building bridges inspires faith and hope that there is a power that is greater than us - the word of God that patiently calls us to preserve creation and the hand of God that ultimately guides in the crisis that we face. 

